penny piece, with clean cut punched-out-looking erloce in the lower third of the ileum. 'The tissues inmediately around the opening were deeply congested. Two large round worms were found alive in the small intestine, and one in the stomach. The perforation was not the result of nlcerative disease. The hole in the gut was circular and ring-like, and quite unlike any solution of continuity from disease. The mucous membrane of the alimentary canal was throughout healthy, and presented no trace of tubercular or other disease. I believe, then, that death was nndoubtedly caused by the worm perforating the bowel.

This last case I reported soon after its occurence in the Indicun Medical Gazette for Decemluer, 1876, and it is alluded to by the late Dr. Norman Chevers in his last pullication, "A Commentary on the Diseases of India." "He also cites a similar case reported by Dr. Edward Birch in the same gazette for $\mathrm{July}, 1878$, when a lunatic died sud denly in the Hazaribagh Asylum, and it was found on postmortem examination that ascarides had escaped through an ulcerated opening in the jejunum into the peritonem. Dr. Chevers says: "It appears questionable whether the worms perforated the intestine in either of the above cases." Dr. Bristowe, in the latest edition of his "Practice of Medicine," says with reference to this entozoon: "It has been asserted that it occasionally perforates the wall of the bowel, and thus finds its way into the peritoneum or some sinus or abscess. It is now, however, generally held that when found in such situations it has simply passed thither through an accidental perforation." Dr. Cobbold says : "In severe cases.... deathly enteritis or perforation of the intestine has been known to occur." As a result of ny own observations in this country, I have no doubt whatever that the round worm is capable of causing perforation of the bowel, and actually boring its way into the peritoneum. Considering the great prevalence of these entozon in Eastern countries and among the dark races generally, the mortality caused by them is, in all probability, greater than is usually supposed. In cholera times they are frequently a predisposing cause of the disease. Calcutta.

\section{AN OBSCURE CASE OF KIDNEY DISEASE.} BY HERBERT J. CAPON, M.D.

ON the evening of May 16th, 1888, I was summoned to see J. M. R_-, aged twenty-six, a young lady who had arrived from abroad six days previously. She gave the following history: Three years ago last Christmas she was confined to her bed with pain in her left side and vomiting. This recurred acutely at her catamenial periods, and was regarded as of liver origin. Her urine, of which from time to time, and generally at the periods of catamenia, she had passed large quantities, was not examined. She suffered at intervals from sickness, and was not considered to be of a strong constitution. On the voyage to England, when the ship was extra "rocky," she was always sick, but this was generally relieved by champagne and rest. She took her food as usual, and drank claret with her meals. She entered into the general amusements during the royage, and danced frequently. There was nothing particularly noticeable in her general state of health. At Gibraltar she suffered from an influenza cold, which she fancied "had struck inwardly." She arrived in England on May 10th. On the morning of the 16 th, on returning from the City in a hansom cab, she complained after dinner of pain in her right iliac and lumbar regions, which was so acute as to necessitate her taking to bed. She was usually constipated, for which she generally found citrate of magnesia an excel lent remedy.

On first seeing the patient, she was lying on her back, perspiring profusely; respiration 24 , attended with pain at the base of the right lung posteriorly; pulse 108, of good volume, regular; temperature $100 \cdot 4^{\circ}$; slight cough, occasionally raising sputum of a rusty colour with considerable effort, but not in any large quantity. The bowels were moved on the day previously. There was no urine to examine. Examination of the chest revealed absolute dulness at the right base up to within three inchess of the inferior angle of the scapula. The respiratory sounds were absent over the dull portion, but tubular at the upper marrin of dulness: 10 rem phony ; rocal iremitus increased lungs in other parts normal; heart sounds normal. There was much tenden ness over the ascending colon, extending backwards, accompanied by some noticeable swelling. Her catamenia were then expected, and, as there was a history of drsmenorrhoea, I preseribed the following mixture: Lig. ammon. acet. conc., 3 dr.; tinc. ferri perchlor., 1 dr. potass. bromid., $1 \frac{1}{3}$ dr.; syr. simplici, 6 dr.; aquam ad $6 \mathrm{oz}$ : a sixth part to be taken every four hours, with $\frac{1}{3}$-gr. morphia pill when in pain. I also had linseed and mustard poultices applied to the back and right flank, and put her upon tluid diet.

May 17th.- The patient had slept fairly well, but perspired profusely. Temperature $101^{\circ}$; pulse 108 ; respiration 24. Had taken nourishment fairly well. Still complained of great pain in the same regions. Ordered to follow the same treatment.

18th.-Condition much the same. Dulness slightly increased upwards. Sputum seanty, and of same character. Catamenia commenced. She stated that she had not micturated for twenty-four hours. No distension of bladder could be made out by nercussion. A hot hip bath was ordered, and a mixture prescribed as follows:- Tinct. opii, $\frac{1}{3} \mathrm{dr}$; tinct. senegre and tinct. scillite of each $2 \mathrm{dr}$; $\mathrm{sp}$. ammon. aromat., 2 dr.; syr. aurantii, 6 dr.; aquam ad 6 oz.; a sixth part to be taken every four hours. In the evening she was not sure whether she had micturated in the bath.

19th.-Had slept well, but rambled at times. Had taken nourishment fairly well. Perspiration still profuse. Easier lying on the left side. Temperature nomal, probalbly owing to the perspiration. Aspect dull, somewhat livid. Passed no urine. Catamenia offensive. The catheter was used, but the bladder was found to be empty. Bowels moved after enema and dose of castor oil.

20th.-Aspect somewhat livid. Perspiration still profuse. Passed no urine. Pain less, owing to morphia. The dulness at the base of the right lung had increased, with similar auscultatory sounds as on the 17th. Slept well through the night, and seemed very drowsy. Perfectly conscious. Had taken nourishment fairly well. Tongue coated with moist white fur. Bowels open after enema.

2lst. - Slept heavily through the night. Temperature $101^{\circ}$; pulse 120 ; respiration 28 . Lividity continues. There is now marked dulness at the base of the left lung also, extending to within three inches of the inferior angle of the scapula. Still no urine passed. Quite clear in intellect, Her condition being extremely grave, I requested a consultation with Sir William Jenner, who saw her at 7.30 P.M. with me, and preseribed the following mixture:-Potass. citratis, 2 dr. ; ammon. chloridi, 1 dr. ; tinct. senegre, 2 dr. ; sp. etheris, 1 dr.; ammon. carb., $20 \mathrm{gr}$.; aquam ad 6 oz. ; one-sixth part to be taken every four hours.

22nd.-She slept fairly well through the night, but gradually sank, dying about $7.30 \mathrm{~A} . \mathrm{M}$.

Inspection made twenty-four hours after death. - Body well nourished. Post-mortem lívidity in patches on the face, around the mouth, and on the dependent parts of the flanks. Abdomen only opened, and about a pint of serous fluid removed. Without disturbance of organs the appearance was as follows:-Creum slightly hyperamic, about two feet of the lower end of the ileum more so, and ascending colon very much so, particularly advancing towards its mesenteric attachment. These portions of intestine were dilated with flatus; no collection in them. On drawing these organs to the left side, an intensely inflamed condition of all structures over the right kidney was observed, with much serous infiltration of areolar tissue. On removing the lidnev, this condition was found to involve the nuseles of the back and the diaphragm, and to extend upwards to the base of the right lung. These parts were softened and sodden. The under and posterior surface of the liver was also darker than normal. The right kiclnev was enlarged, softened, acutely inflamed, and on remoral was found distended with urinary secretion. One saceule was ruptured, from which escaped six or eight ounces of fluid. The left kidney was found enormously dilated, sacculated, and full of fluid. The pe'vis was dilated to the size of a hen's egg, and the ureter was as large as one's thumb, being plugged at its point of crossing the psoas muscle and common iliac vein with a calculus slimhtly larger than a rifle bullet, and of the same shape. This condition had undoubtelly exinted for some considerable time, as the adhesions were old and tomoh, and required much care in dissecting the ureter away. The i ght kidney weighed $15 \frac{1}{2} 0 z$. It substance was softened 
and disintegrated. The capsule was adherent all over, but stripped off with tearing away of kidney structure, leaving the surface granular and soft. At the upper part was an abscess apparently as large as a hen's egg, which was ruptured in removal, and constituted the "sae" above named. The infundibula were much dilated, and contained one largeirregular calculus, weighing nearly $\frac{1}{3}$ oz., with about 140 others varying in size from a horse-bean to a millet-seed. In the ureter, about two inches below the kidney, were three calculi, one completely blocking the lumen. The left lidney weighed, with ureter, fluid, and plugging calculus, $17 \mathrm{oz}$; ; without the last two, $6 \frac{1}{2} \mathrm{oz}$. The calculus weighed $52 \mathrm{gr}$. The difference consisted simply of clear straw-coloured fluid. There was not the slightest trace of kidney substance left, being simply one large fibro-capsular, inultilocular cyst. The right ovary weighed a little over $1 \mathrm{oz}$., was irregularly cystic, and had applied to it the fimbriated extremity of that Fallopian tube (catamenia present). The left ovary weighed $\frac{3}{4} \mathrm{oz}$, and was also cystic. There was no rupture of a Graafian vesicle on either. The ovarian capsules seemed somewhat thickened and tougher than natural. On the fundus of the uterus was a small subperitoneal fibroid as large as a pea. The spleen, intestines (beyond the inflamed part), and other organs were apparently normal. 'The bladder was empty and contracted.

In the family history, one finds that the mother died two years ago of uterine tumour, stated to be fibroid and of rapid growth, nine months after its existence had been discovered The father is living, but has had two attacks of gout. One brother died, aged four, of stone in the bladder, thirty years ago, unrelieved. Two children died of diphtheria and croup during infancy, and one of scarlatina. An elder sister is at present suffering from uterine tumour, and is to undergo treatment at the hands of Sir Spencer Wells, Bart.

Edgware-road, W.

\section{A NEW AND RATIONAL TREATMENT FOR GONORRHEEA.}

BY CHARLES J. SMITH, FORMERLY SURGEON TO THE FARRINGDON DISPENSARY.

From causes, not far to seeli perhaps, urethral affections of a specific character have been sorely neglected by the general body of surgeons, and left almost entirely in the hands of a few specialists, who probably have become such by the accident of their obtaining appointments at institutions of a special character, rather than by any choice or predilection for the class of cases which there fall to their lot. It cannot, therefore, be wondered at that so little has been done to reduce the treatment of an affection such as gonorrhoea to something like an exact science. An approach to a better line has been made of late in the use of medicated bougies; but the objections to these are the time requisite for their proper application, and the difficulty of thoroughly carrying out the necessary details to ensure the absolute disinfection of the affected tract. It was, however, starting from this point that I concluded there must be a way of dealing with gonorrhoea which shoull be at once effective and effectual. It occurred to me then that if remedies were made up in the form of an ointment and introdnced by a proper instrument the difficulties would in all probability be overcome. Taking Allingham's rectal ointment-introducer as the key, I had made for me, by Messrs. Arnold and Son, an instrument which has proved perfectly efficient. I am now able to treat my cases with marked success; and, indeed, the average duration of the attacks is so short as to appear open to question - an average of five days, --but even in this I feel convinced that the best point is not reached. I shall be both astonished and disappointed if gonorrhoea, as such, will not be absolutely killed in a couple of days. Gonorrhcea is a specific inflammation; it is to be attacked by means that will disinfect and destroy its special virus, or perhaps I shall be more correct in saying that will kill its special micrococci. A thorough disinfection of the pus-generating, or micrococei-breeding area may, I believe, be obtained by two applications, and there will be left at most a simple and very mild inflammation to be dealt with. In the cases I have already treated by this new method I have had only a thin watery discharge left in exchange for the purulent one after two or three days, and I question whether it really will prove necessary to make use of the weak astringent injection which, for the present, I prescribe for safety's sake. The accompanying woodcut shows the instrument. Each ointment-container-an oblong box with a long broad screw to expel its contents-has stems made in various sizes, all of which fit the ointment-container; so that, as with catheters, the size proper for each patient may be chosen; and this is one point of prime importance in the treatment which I would enforce. The urethra must be stretched by as large a stem as can be introduced; the object of this is that the whole of the surface may be made as tense as possible, and the ointment spread fairly and well over every portion. The bladder should be enptied immediately before the instru-

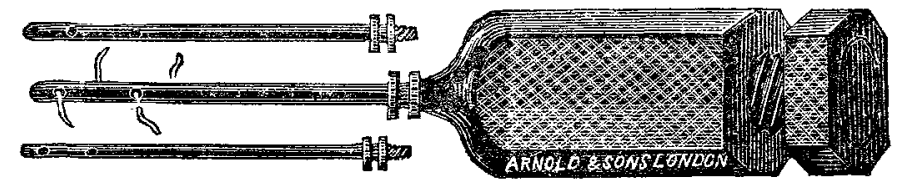

ment is used, so that the urethra is well washed out from behind. The stem is to be well oiled before introduction. I use a mixture of eucalyptus and olive oils. When the stem is as far in as appears necessary, the ointment is pressed out, and the whole instrument rotated as it is withdrawn, in order that the canal may be thoroughly wiped over. A little cotton wool and the usual dressing are employed to collect the discharce; and after three hours a mild injection is given, which is repeated four or five times during the day. A second use of the ointment is made on the following morning, and the injection repeated. The only medicine given is a saline aperient. I have found no need for copaiba, or the almost equally disagreeable sandal wood.

Before leaving this subject I desire to put on record a firm conviction which I have formed from a fairly long experience in practice. It is that a very considerable number of cases of gonorrhcea in the male are never really cured. The treatment apparently succeeds, and the patients are either discharged as cured, or, considering themselves well, cease further treatment. I believe that in these cases an attenuated form of gonorrhoea remains, and may remain for year. A man under these circumstances marries, and infects his wife; the wife possibly complains of irritation and "whites," although exanination of the discharge will almost invariably show it to be yellow. Now the husband has attained his tolerance, and therefore is not necessarily, in his turn, greatly affected by the wife's condition. Over and over again I have met with these cases, anil no better illustration of what I mean can be given than the case of a gentleman who recently caine under my care. He was married about a year ago. He offered for my inspection a mild sample of what was mndonbtedly gonorrhoa, sayins that he had derived the discharge from his wife soon after marriage, owing to her having "come on unwell during connexion"; aud, mark, this is the most common cause assigned in these cases. Doubting this, I pressed him, but he firmly, and I belie. e truthfully, avowed that he had been faithful. $\mathrm{He}$ acknowledged gonorrhcea prior to marriage, but considered he had quite got rid of it. His wife had always complained of irritation and "whites." She had lately been confined. I immediately asked as to the child's eyes after birth. The reply was just what I expected: "there was great discharge," but, thanks to a good and experienced nurse, this had ceased after due and careful treatment.

In all cases of married women who complain to me of leucorrhosa, I invariably prescribe the use of a uterine doashe, with a disinfectant and astringrent, night and morning. It is of course unnecessary to alam them in any way, but I have grown to consider it a duty to take this view of every case of the kind which comes under my notice, so strongly am I persuaded that this conviction of mine is only too well founded.

Great St. Helens, E.C.

Provincial Hospital Saturday Collections.The annual Hospital Saturday collection at Leamington, on behalf of the local hospital, was made on the 18th ult., and about $£ 85$ were collected at the street stands. The total amount of the collection is not yet known. The recent Hospital Saturday street collection at Portsmonth amounted to $\pm 2716 s .3 d$, an increase of $£ 10$ on last year. 